EMPOWER : Jurnal Pengembangan Masyarakat Islam

Vol. 5, No.1, Juni 2020, hlm. 25-42

e-ISSN : 2580-0973, p-ISSN : 2580-085X

Tersedia Online di : http://syekhnurjati.ac.id/jurnal/index.php/empower

Email : empowerjurnal@gmail.com

\title{
Rasionalitas Sosial-Ekonomi Masyarakat Muslim Glagah: \\ Studi Kasus New Yogyakarta International Airport Di Kulon Progo, D. I. Yogyakarta
}

\author{
Muchamad Agus Munir* \\ (Program Studi Pemikiran Pendidikan Islam, Fakultas Pendidikan Islam, \\ Universitas Sains Al-Qur'an Wonosobo) \\ E-mail: siapamirat@gmail.com,
}

\section{Ilyasi**}

(Program Studi Sosiologi Agama, Fakultas Ushuluddin dan Pemikiran Islam, UIN

Sunan Kalijaga Yogyakarta)

E-mail: ilyasmahpu@gmail.com

\section{Article History}

Submitted: 29.04.2020; Revised:14.06.2020; Accepted: 21.06.2020;

\begin{abstract}
This study aims to describe and provide understanding that the construction of the New Yogyakarta International Airport is a conflict of interest between the government and capital owners with local Muslim communities. The conflict created a social space that was different from the socio-historical space of the local community. The method used in this research is field research with a sociological approach, primary data sources for interviews, observation and documentation, secondary data with books, journals and websites, and data analysis techniques using content analysis. The time spent in research is around 3 months, March-May 2019. The results of the study show that with the development of NYIA, a new social space was formed which according to Henry Lavebre's theory is, (1) Spatial Practices and Construction of City-Based Development, meaning that there is a change in life around the airport is especially related to capital owners. They will be free to control and determine life. (2) Construction and Contestation of Economic Development, the intention is a change in economic terms, from traditional to modern. (3) Abstract Space
\end{abstract}


Glagah Village, a capitalization that is not realized by the local community, especially in the economic, political and lifestyle fields. (4) NYIA Space Contradiction, uncertainty for the lower middle class in the pattern of life, this is due to more control by capital owners. (5) Reproduction of Religious Spaces. Only people who have power over places of worship can obtain or have the right to manage and utilize religious facilities collected under the pretext of caring for and developing religion around the airport.

Keyword: Development, NYIA, Social Space Production.

\begin{abstract}
Abstrak
Penelitian ini bertujuan untuk mendeskripsikan dan memberikan pemahaman bahwa pembangunan Bandara New Yogyakarta International Airport merupakan sebuah konflik kepentingan antara pemerintah dan pemilik modal dengan masyarakata muslim setempat. Koflik tersebut menimbulkan sebuah ruang sosial yang berbeda dengan ruang sosio-historis masyarakat setempat. Metode yang digunakan dalam penelitian adalah field research dengan pendekatan sosiologis, sumber data primer wawancara, observasi dan dokumentasi, data sekunder dengan buku, jurnal dan website, serta teknik analisis data menggunakan analisis content. Waktu yang digunakan dalam penlitian sekitar 3 bulan yaitu bulan Maret-Mei 2019. Hasil penelitian menunjukkan bahwa dengan pembangunan NYIA, terbentuk sebuah ruang sosial baru yang menurut teori Henry Lavebre yaitu, (1) Praktik spasial dan Kontruksi Pembangunan Berbasis Kota, artinya adanya perubahan dalam kehidupan di sekitar Bandara khusunya berkaitan dengan pemilik modal. Mereka akan leluasa mengendalikan dan menentukan kehidupan. (2) Konstruksi dan Kontestasi Pembangunan Ekonomi, maksudnya adalah adanya perubahan dalam hal ekonomi, dari tradisional menuju modern. (3) Ruang Abstrak Desa Glagah, adanya kapitalisasi yang tidak disadari masyarakat setempat, terutama dalam bidang ekonomi, politik dan gaya hidup. (4) Kontradiksi Ruang NYIA, ketidakpastian bagi kelas menengah ke bawah dalam pola hidup, hal ini disebabkan pengauasaan yang lebih oleh pemilik modal. (5) Reproduksi Ruang Agama. Hanya orang yang mempunyai kekuasaan terhadap tempat ibadah yang dapat memperoleh atau
\end{abstract}


mempunyai hak untuk mengelola dan memanfaatkan fasilitas agama yang terkumpul dengan dalih merawat dan pengembangan keagamaan di sekitar bandara.

Kata kunci: Pembangunan, NYIA, Produksi Ruang Sosial.

\section{PENDAHULUAN}

Menurut Mansour Fakih, pembangunan merupakan suatu teori di bawah payung teori perubahan sosial. Secara lambat laun, pembangunan sebagai suatu teori berubah menjadi suatu pendekatan dan ideologi, bahkan menjadi suatu paradigma dalam perubahan sosial. Di satu sisi, pembangunan adalah sebuah teori, di sisi lain pembangunan merupakan ideologi Orde Baru bahkan dijadikan sebagai nama kabinet selama kekuasaan Orde Baru di bawah Presiden Soeharto ${ }^{1}$.

Pada era ini, pemerintahan Jokowi kembali melanjutkan sosok pemimpin developmentalis dengan varian yang berbeda. Semenjak pemerintahan Jokowi, kata pembangunan kembali mengemuka sebagai sebuah wacana yang dominan². Hasrat pembangunan terlihat dari 225 proyek strategis nasional yang tertuang dalam Perpres nomor 3 tahun 2016 tentang percepatan pelaksanaan proyek strategis nasional, di antaranya: 47 pembangunan ruas jalan tol, 11 pembangunan sarana dan prasarana kereta api antar kota, 6 pembangunan infrastruktur kereta api dalam kota, 12 pembangunan pelabuhan, 59 pembangunan bendungan, 24 pembangunan kawasan industri, 10 proyek revitalisasi bandar udara, 4 pembangunan bandar udara baru, dan beberapa proyek lain. Salah satu pembangunan bandar udara baru tersebut terletak di Daerah Istimewa Yogyakarta ${ }^{3}$. Selain itu, anggaran APBN pada tahun 2017 untuk anggaran infrastruktur

1 Mansour Fakih, Runtuhnya Teori Pembangunan Dan Globalisasi Cet. VIII (Yogyakarta: Pustaka Pelajar, 2013), pp. 13-14.

2 Muhammad Azka Gulsyan, 'Ekonomi-Ekonomi Yang Lain: Mewacanakan Ekonomi Dan Melihat Kembali Pembangunan' <indoprogress.com>.

${ }^{3}$ Peraturan Presiden Republik Indonesia Nomor 3 Tahun 2016 Tentang Percepatan Pelaksanaan Proyek Strategis Nasional. 
mencapai Rp 387.3 triliun ${ }^{4}$. Angka tersebut mengalami kenaikan sebesar Rp. 70,2 triliun daripada tahun 2016 (sebesar 317.1 triliun).

Fenomena pembangunan NYIA menimbulkan kontestasi, negosiasi, konsensus, dan konflik. Berdasarkan perspektif Henri Lefebvre dengan pendekatan sosio-parsial, hal tersebut dapat dipahami sebagai bentuk relasi kuasa dari aktor-aktor penataan ruang yang meliputi pemerintah, masyarakat, dan pasar ${ }^{5}$. Hal tersebut menunjukkan bahwa pembangunan NYIA dapat memberikan pemahaman mengenai sinergi pemerintah lokal (Kabupaten Kulon Progo) dan pemerintah pusat dengan kekuatan kapital dalam mengembangkan kawasan pariwisata, real estate, dan sebagainya.

Urgensi penelitian ini berdasarkan atas beberapa alasan akademik: Pertama, pembangunan NYIA menjadi lahan baru yang dibuka pemerintah untuk investor asing. Kedua, kemungkinan adanya perubahan masyarakat yang cukup signifikan, khususnya masyarakat muslim Glagah. Ketiga, fenomena penataan ruang sosial ekonomi dalam pembangunan NYIA di Kulon Progo sangat dipengaruhi oleh kepentingan modal kapitalis, sehingga masyarakat kehilangan hak atas tanahnya.

Berdasarkan alasan akademik tersebut, penelitian ini diharapkan mampu menjadi salah satu bagian untuk mengubah realitas sosial, seperti yang pernah diungkapkan oleh Mansur Fakih bahwa tugas utama teori sosial tidak sekedar memberi makna terhadap realitas sosial, melainkan mempunyai tugas untuk mengubah realitas sosial yang dianggap mengalami problem sosial. Berdasarkan perspektif teori kritis, ilmu sosial tidaklah sekedar dimanfaatkan untuk mengangkat kepentingan golongan lemah dan tertindas, namun teori sosial semestinya berperan dalam proses pembangkitan kesadaran kritis, baik yang tertindas maupun yang menindas, terhadap sistem dan struktur sosial yang tidak adil. Artinya, teori sosial harus mengabdi pada proses transformasi sosial, yaitu terciptanya hubungan (struktur) yang baru dan lebih adil ${ }^{6}$.

\footnotetext{
${ }^{4}$ Kementerian Keuangan Republik Indonesia, 'Perekonomian Indonesia Dan APBN 2017'<www.kemenkeu.go.id> [accessed 2 September 2018].

5 Siti Aminah, 'Konflik Dan Kontestasi Penataan Ruang Kota Surabaya', MASYARAKAT: Jurnal Sosiologi, 2016.

${ }^{6}$ Fakih, pp. 5-9.
} 


\section{Fakta Tentang NYIA}

Riset mengenai pembangunan New Yogyakarta International Airport sudah banyak dilakukan, seperti riset yang dilakukan oleh Anisa Nurpita(dkk.) yang berjudul "Dampak Alih Fungsi Lahan Terhadap Ketahanan Pangan Rumah Tangga Tani Di KecamatanTemon Kabupaten Kulon Progo". Hasil penelitian yang menunjukkan bahwa sebelum dan pembangunan NYIA tidak terdapat perbedaan ketahanan pangan, namun jika dilihat dari olah data statistika deskriptif terlihat ada penambahan jumlah rumah tangga tani yang rawan pangan setelah adanya alih fungsi lahan untuk pembangunan NYIA di Kulon Progo ${ }^{7}$.

Wahyu Kustiningsih menganalisis mekanisme yang dapat mengakomodasi kepentingan kelompok rentan, sehingga dapat berpartisipasi dalam pembangunan di kawasan bandara. Maka, riset ini menghasilkan tiga rekomendasi, yaitu: keperluan adanya grand design pembangunan bandara yang mempertimbangkan keberlanjutan kelompok rentan, inisiasi program community development guna memberdayakan kelompok rentan, dan perlunya perumusan kebijakan afirmatif bagi kelompok rentan dengan mendasarkan pada asas keadilan sosial ${ }^{8}$. Menurut Rahmad Hidayat, pembangunan NYIA berpotensi melanggar hak-hak ekonomi, sosial, dan budaya warga negara. Hal ini dijelaskan dalam risetnya yang berjudul "Potensi Pelanggaran Hak Atas Properti Privat dalam Pembangunan Fasilitas Publik (Kasus Pembangunan Bandara International Kulon Progo)". Riset ini menunjukkan hak yang dilanggar pemerintah meliputi hak rumah dan tanah individu. Pelanggaran tersebut terwujud dalam bentuk penggusuran paksa yang dilakukan oleh

${ }^{7}$ Anisa Nurpita and dkk, 'Dampak Alih Fungsi Lahan Terhadap Ketahanan Pangan Rumah Tangga Tani Di Kecamatan Temon Kabupaten Kulon Progo', Jurnal Gama Societa, 2018, vols 1 No.1, Januari 2018.

8 Wahyu Kustiningsih, 'Kelompok Rentan Dalam Pembangunan Kawasan Kota Bandara Di Kulon Progo: Studi Kasus New Yogyakarta International Aiport (NYIA)', Jurnal Pemikiran Sosiologi, 2017, vols 4, No. 1. 
pemerintah untuk mengambil aset dan tanah warga yang didefinisikan sebagai lokasi untuk pembangunan fasilitas umum.

Senada dengan riset di atas, Anjar Mukti Yuni Pamungkas dalam "Manajemen Konflik dan Negosiasi Wajah dalam Budaya Kolektivistik (Konflik Pembangunan Bandara di Kulon Progo)", Penelitian ini memberikan gambaran terkait manajemen konflik dan negosiasi wajah dalam budaya kolektivitas, sehingga dapat ditarik ke dalam beberapa kesimpulan, yakni: Pertama, manajemen konflik yang dilakukan oleh masyarakat Kecamatan Temon melalui dua cara, yaitu penghindaran dan pengungkapan emosi. Kedua, berdasarkan kedua cara manajemen konflik tersebut, cara penghindaran lebih dominan digunakan oleh masyarakat. Ketiga, adanya komunikasi yangterpolarisasi, timbulnya suatu anggapan bahwa kutub "kita" sebagai kutub superior dan kutub "mereka" sebagai kutub inferior ${ }^{10}$.

\section{Produksi Ruang Publik (The Production of Space)}

Konsepsi mengenai ruang mendapatkan perhatian yang dominan sejak Henri Lefebvre ${ }^{11}$ mempublikasikan The Production of Space (diterjemahkan ke dalam Bahasa Inggris pada tahun 1991). Karya ini merupakan salah satu kritik terhadap konsepsi Karl Marx mengenai produksi. Prediksi Marx belum terbukti tentang kehancuran kapitalisme yang disebabkan oleh kontradiksi internalnya. Kapitalisme mampu bertahan walaupun dipukul krisis besar, bahkan mampu lolos dari kondisi

9 Rahmad Hidayat, 'Potensi Pelanggaran Hak Atas Properti Privat Dalam Pembangunan Fasilitas Publik (Kasus Pembangunan Bandara International Kulon Progo)', Journal of Governace, 2017, vols 2, No. 1.

${ }^{10}$ Anjar Mukti Yuni Pamungkas, 'Manajemen Konflik Dan Negosiasi Wajah Dalam Budaya Kolektivistik (Konflik Pembangunan Bandara Di Kulon Progo)' (Universitas Diponegoro, 2015).

11 Henri Lefebvre (1901-1991) adalah Sosiolog Marxis kelahiran Perancis, dan melahirkan banyak kritik atas teori Marxis Klasik. Henri Lefebvre melakukan tinjauan atas masalah spasialitas kota yang banyak memberikan perubahan terhadap pandangan teori urban klasik era modern. Pemikirannya dituangkan dalam dua karya, yakni The Critique of Everyday Life, Volume 1 (1947), diterjemahkan John Moore pada tahun 1991. Serta buku The Production of Space (1974), diterjemahkan oleh Donald Nicholson Smith pada tahun 1991. 
tersebut. Henri Lefebvre menilai bahwa kapitalisme dapat bertahan hidup lewat penciptaan perluasan ruang ${ }^{12}$.

Pemikiran Henri Lefebvre mengenai ruang merupakan perluasan dari pembagian ruang dualis menurut Descartes yang membagi realitas menjadi dua, yaitu res extensa (sebuah keleluasaan yang menempati suatu ruang dan waktu, atau disebut sebagai perwujudan material), dan res cogitan (proses penyangkalan terhadap realitas material tersebut). Res cogitan adalah ruang yang lahir dari subyektivitas spiritual suatu obyek rasional, yakni manusia.

Bagi Henri Lefebvre, ruang merupakan komponen dari tiga aspek dikenal dengan triadic of space yang menjadi pilar dari epistemologi dari produksi ruang, yaitu: representation of space, space of representation dan spatial practice. Konsep representation of space merujuk pada ruang yang terkonsepsi yang dilakukan oleh para profesional dan teknokrat, seperti arsitek, perencana kota, insinyur, pengembang atau geographer, maupun birokrat lain. Henri Lefebvre menamakan space of representation sebagai lived space, yaitu merujuk pada ruang yang ditempati atau ruang yang ditinggali sehari-sehari ${ }^{13}$. Spatial practices merupakan rangkaian tindakan dan interelasi yang tersembunyi dalam ruang-ruang masyarakat, ruang-ruang interaksi dialektikal antar anggota masyarakat. Henri Lefebvre menyebut spatial practice merangkul produksi maupun reproduksi, konsepsi dan eksekusi, dibayangkan dan dijalani, semua itu memastikan terjadinya kohesi sosial, keberlanjutan masyarakat dan social competence, yaitu hubungan setiap anggota masyarakat terjamin keberlanjutannya dan berada dalam derajat yang sama dalam suatu ruang sosial ${ }^{14}$.

Pada akhirnya, ruang itu menjadi alat produksidan terdapat jaringan pertukaran komoditas. Demi mendapatkan sebuah ruang produksi baru, maka abstraksi sejak awal dimulai dengan cara memisahkan realitas

\footnotetext{
12 David Harvey, Imperialisme Baru Genealogi Dan Logika Kapitalisme Kontemporer (Sleman: Resist Book, 2010), p. 97.

${ }_{13}$ Yoppie Christian and Desmiwati Desmiwati, Menuju Urbanisasi Pulau, p. 52.

${ }^{14}$ Henry Lefebvre, The Production of Space; Translated by Donald Nicholson, Urban Studies (Oxford: Blackwell, 33 <https://doi.org/10.1080/00420989220081001>.
} 
fisik dan mental, antara ruang fisik dan manusia semua menjadi alat produksi. Cara yang paling efektif adalah dengan cara memobilisasi pengetahuan, kapital, hukum, dan politik dalam sebuah praktik perampasan secara terus menerus. Proses perampasan berjalan secara terus menerus untuk menghancurkan setiap sejarah suatu masyarakat, menghancurkan keragaman di dalamnya, tujuannya adalah mewujudkan homogenitas abstrak ${ }^{15}$.

Teori ruang dari pemikiran Henri Lefebvre ini digunakan untuk membongkar kondisi yang terjadi pada masyarakat muslim Glagah, persaingan, dan konflik, serta perubahan fungsi ruang pada masyarakat dalam pembangunan New Yogyakarta International Airport di Kecamatan Temon, Kulon Progo, Daerah Istimewa Yogyakarta.

Jenis penelitian ini adalah penelitian kancah atau penelitian lapangan. Dengan demikian, penelitian ini dilakukan langsung di Desa Glagah, Kecamatan Temon, Kulon Progo, Daerah Istimewa Yogyakarta. Sedangkan pendekatan yang digunakan adalah pendekatan "sosiologis" sebagai upaya untuk melihat produksi ruang sosial dan kontestasi ekonomi dalam pembangunan New Yogyakarta Internasional Airport di Kecamatan Temon, Kulon Progo, Daerah Istimewa Yogyakarta. Sumber data penelitian ini dibagi menjadi dua bagian, yaitu data primer dan data sekunder. Data primer adalah sumber pertama yang diperoleh langsung dari masyarakat Desa Glagah, Kecamatan Temon, Kulon Progo. Data sekunder merupakan sumber data kedua sesudah data primer. Sumber data sekunder diharapkan dapat membantu memberi keterangan, atau data pelengkap sebagai pembanding ${ }^{16}$. Maka data sekunder dalam penelitian ini diperoleh dari berbagai hasil penelitian sebelumnya yang berkaitan dengan tema pembangunan NYIA di Kulon Progo. Data sekunder juga diperoleh dari media, baik media cetak maupun media internet yang memberitakan tentang pembangunan mega proyek NYIA di Kulon Progo. Teknik pengumpulan data diperoleh melalui observasi langsung, wawancara, dan

\footnotetext{
15 Yoppie Christian and Desmiwati Desmiwati, 'Menuju Urbanisasi Pulau Kecil: Produksi Ruang Abstrak Dan Perampasan', Journal of Regional and Rural Development Planning, 2018, p. 54 <https://doi.org/10.29244/jp2wd.2018.2.1.45-63>.

${ }^{16}$ Burhan Bungin, Metodologi Penelitian Sosial, pp. 128-129.
} 
dokumentasi. Data yang terkumpul kemudian dianalisis dengan menggunakan teknik yang diterapkan oleh Miles dan Huberman, yaitu mencakup tiga tahapan, yaitu reduksi data, displasi data, dan verifikasi data $^{17}$.

\section{HASIL DAN PEMBAHASAN}

\section{Profil New Yogyakarta International Airport (NYIA)}

New Yogyakarta International Airport (NYIA) dibangun di Kecamatan Temon, Kabupaten Kulon Progo, Daerah Istimewa Yogyakarta. Berdasarkan pendataan, luas tanah yang dibutuhkan untuk pembangunan NYIA adalah $\pm 145,63 \mathrm{Ha}$, dengan perincian sebagai berikut; Desa Glagah seluas $\pm 2.936,841 \mathrm{~m}^{2}$, Desa Palihan seluas $\pm 2.086 .866 \mathrm{~m}^{2}$, Desa Sindutan seluas $\pm 622.409 \mathrm{~m}^{2}$, Desa Jangkaran seluas $\pm 492.237 \mathrm{~m}^{2}$, dan Desa Kebonrejo seluas $\pm 317.938 \mathrm{~m}^{2}$. Data ini menunjukkan bahwa Desa Glagah merupakan wilayah paling banyak untuk pembangunan bandara NYIA ${ }^{18}$.

Pembangunan bandara baru di Yogyakarta merupakan program strategis nasional $^{19}$, pelaksanaannya dimandatkan kepada Pemda DIY,

17 Moh. Soehadha, Metodologi Penelitian Sosiologi Agama (Yogyakarta: Bidang Akademik UIN Sunan Kalijaga, 2008), pp. 113-15.

18 Jumlah pedukuhan di Desa Glagah yang terdampak langsung adalah Dusun Kepek dan Dusun Bapangan berupa tanah pemukiman dan pertanian. Sedangkan dusun lain yang ada di desa Glagah yang terdampak secara tidak langsung berupa tanah pertanian.

19 Pembangunan dan pengoperasian Bandara Baru di Kulon Progo, D.I. Yogyakarta merupakan salah satu Proyek Strategis Nasional yang perlu segera dilakukan percepatan pembangunan dan pengoperasiannya melalui penugasan Badan Usaha Milik Negara. Oleh sebab itu, ditetapkan Peraturan Presiden Republik Indonesia Nomor 98 Tahun 2017 tentang "Peraturan Presiden tentang Percepatan Pembangunan dan Pengoperasian Bandar Udara Baru di Kulon Progo Provinsi Daerah Istimewa Yogyakarta". Pada pasal 1 ayat 1 dalam ketetapan tersebut disebutkan bahwa percepatan pembangunan dan pengoperasian Bandar Udara Baru di Kabupaten Kulon Progo Provinsi Daerah Istimewa Yogyakarta dilakukan untuk peningkatan konektivitas, pengembangan infrastruktur penerbangan, dan pengembangan wilayah Provinsi Daerah Istimewa Yogyakarta. Kemudian pada ayat 2 disebutkan bahwa pembangunan Bandar Udara Baru di Kabupaten Kulon Progo Provinsi Daerah Istimewa Yogyakarta merupakan bandar udara umum untuk domestik dan internasional. 
Kulon Progo, dan PT. Angkasa Pura $\mathrm{I}^{20}$. Secara umum, tujuan pembangunan NYIA adalah menyediakan bandara baru yang representatif, memenuhi standar badan penerbangan internasional, serta mampu mendorong pertumbuhan ekonomi dan perkembangan wilayah sekitar Kulon Progo, Daerah Istimewa Yogyakarta, dan Jawa Tengah bagian selatan $^{21}$.

Pembebasan lahan untuk pembangunan NYIA berbau "perampasan tanah" masyarakat Temon, Kulon Progo ${ }^{22}$. Kronologinya bermula pada tanggal 27 Januari 2017, Presiden Jokowi melakukan upacara peletakanbatu pertama proyek NYIA. Kemudian pada tanggal 23 Oktober 2017, Jokowi menerbitkan Peraturan Presiden nomor 98 tahun 2017 tentang Percepatan Pembangunan dan Pengoperasian Bandar Udara di Kabupaten Kulon Progo.

\section{Produksi Ruang Sosial Baru Masyarakat Muslim Glagah Dampak Ekonomi Bagi Masyarakat}

Dampak ekonomi bagi masyarakat dapat dilihat dari beberapa pendapat warga Desa Glagah yang bersedia diwawancarai. Menurut Arto, dampak ekonomi bagi masyarakat belum terlalu terlihat. Menurutnya, yang sudah mulai tampak meningkat perekonomiannya adalah masyarakat yang tidak terdampak secara langsung dan masyarakat yang memang mempunyai modal ${ }^{23}$. Hadi Sentono, mengatakan bahwa:

“Tanah yang dibeli oleh Angkasa Pura permeter hanya 500 ribu, tanah untuk membangun rumah baru di sini harus beli 850 ribu per meter. Sebelumnya sayasendiri punya tanah sebanyak 6 petak, setelah dibeli Angkasa Pura, uangnya hanya cukup untuk membeli tanah baru ini, ya ini

\footnotetext{
20 PT. Angkasa Pura I adalah Badan Usaha Milik Negara (BUMN) yang diberi mandat untuk mengelola empat belas (14) bandara di kawasan Tengah dan Timur Indonesia.

${ }^{21}$ Akademia, New Yogyakarta International Airport: Pesisir Selatan Temon-Kulon Progo, 2017, p. 4.

22 Tim Penutur Selamatkan Bumi, 'New Yogyakarta International Airport: Pembangunan Tanpa Demokrasi, Pembangunan Tanpa Rakyat' $<$ selamatkanbumi.com>.

23 Wawancara dengan Bapak Arto, warga Desa Glagah, di Glagah tanggal 10 Januari 2019.
} 
untuk dibangun rumah. Kan enggak cukup untuk membeli tanah sebanyak enam petak lagi, karena harga tanah naik semua"24.

Berdasarkan hasil wawancara di atas, dampak ekonomi dari pembangunan NYIA tidak berdampak positif bagi masyarakat secara umum. Namun hanya berdampak positif bagi sebagian kelas saja. Bagi masyarakat yang memang hidupnya bergantung pada hasil mengolah tanah, justru pembangunan NYIA merupakan proses perampasan terhadap ruang ekonomi mereka. Ruang ekonomi masyarakat diambil alih oleh pemerintah bersama pemilik modal dengan prinsip untuk meningkatkan ekonomi suatu daerah. Akan tetapi, prinsip tersebut tidak dapat dinikmati oleh masyarakat secara keseluruhan. Sebab, di satu sisi tidak mudah untuk beralih profesi. Sedangkan di sisi yang lain, masyarakat memang tidak mempunyai modal secara ekonomi untuk ikut terlibat dalam perkembangan ruang yang berbasis kota ini.

\section{Mental Masyarakat Muslim}

Henri Lefebvre berpandangan bahwa produksi dan reproduksi kapitalis menghasilkan spasial praktik. Konsepsi ruang inimerujuk pada hasil dari kegiatan, perilaku, dan pengalaman sehari-hari masyarakat. Praktik spasial dapat dikatakan sebagai bentuk ruang secara fisik, ruang nyata, ruang yang dihasilkan dan digunakan oleh masyarakat. Praktik spasial ini dapat diidentifikasi sebagai ruangyangmenunjukkanmaterial atau fisik yang dapat diindra dan dipersepsikan dalam kehidupan seharihari $^{25}$.

Problem yang muncul di Desa Glagah, ruang fisik yang semestinya digunakan untuk ruang hidup masyarakat lambat laun menjadi ruang yang beralih sifatnya untuk kegiatan ekonomi, pada tahap ini praktik spasial telah terjadi di Desa Glagah.Pemerintah secara sadar mengambil alih fungsi dari ruang fisik-khususnya tanah masyarakat muslim Desa Glagah dan 2019.

${ }^{24}$ Wawancara dengan Hadi Sentono, petani, di Glagah tanggal 10 Januari

${ }^{25}$ Zul Azhar, 'Kajian Lingkungan Dan Perencanaan Pembangunan', in Buku Ajar Fakultas Ekonomi Universitas Negeri Padang, 2017, p. 9. 
sekitarnya-untuk pembangunan yang akan bernilai ekonomi. Berdasarkan pandangan Lefebvre, hal ini yang dimaksud sebagai produksi ruang sosial, yaitu proses memproduksi ruang yang dilakukan melalui relasi produksi pada sebuah relasi dan praktik sosial, maka Desa Glagah akan terus memproduksi ruangnya.

Di satu sisi, pembangunan yang dirancang oleh pemerintah memang bagus untuk meningkatkan ekonomi masyarakat. Namun di sisi yang lain, pembangunan ini membawa dampak negatif, termasuk perilaku dan sikap keagamaan masyarakat muslim. Berdasarkan hasil wawancara dengan Kasimin, masyarakat sudah siap secara mental untuk menghadapi sisi negatif dari pembangunan NYIA. Sebab, masyarakat sejak awal melakukanpenolakannamun tidak berhasil, jadikedepannya masyarakat akan tetap berupaya menjaga lokalitas, meskipun hal tersebut tentu tidak akan seperti yang diharapkan oleh masyarakat ${ }^{26}$. Setiap pembangunan tentu mengorbankan nilai-nilai kedaerahan, bagi Henri Lefebvre hal ini disebut dengan homogenitas, menghilangkan nilai-nilai tradisional, diuniversalkan dengan nilai-nilai baru yang ditentukan oleh tangan-tangan kapitalis.

\section{Kontestasi Ekonomi dan Dampak Terhadap Nilai-Nilai Keagamaan Masyarakat Glagah}

\section{Praktik spasial dan Kontruksi Pembangunan Berbasis Kota}

Pembangunan kota pada abad 21 ini, menurut Henri Lefebvre ada kecenderungan yang mengarah pada kota kapitalis (modern) ${ }^{27}$. Ruangruang masyarakat dikuasai oleh berbagai kepentingan, bahkan menafikan kepentingan pemilik ruang itu sendiri, seperti yang terjadi di Desa Glagah.Ruang-ruang sosial masyarakat dirampas dengan dalih pembangunan yang berbasis kota. Para pemilik modal datang untuk menguasai atau memanfaatkan ruang-ruang yang dimiliki oleh masyarakat lokal. Pertumbuhan ruang-ruang baru bukan diciptakan oleh masyarakat lokal, melainkan oleh orang-orang pendatang yang memiliki kemampuan

${ }^{26}$ Wawancara dengan Kasimin, di Glagah tanggal 10 Januari 2019.

27 Aminah, p. 66. 
dan modal untuk mendirikan berbagai bentuk usaha yang sesuai dengan perkembangan pasar. Ke depan, praktik spasial yang dilakukan oleh orangorang luar Kulon Progo akan semakin pesat perkembangannya, mereka akan datang untuk membeli atau menyewa tanah-tanah milik masyarakat lokal. Ruang dikonstruksi sedemikian rupa sebagai sarana pemikiran dan tindakan untuk melanggengkan kekuasaan dan menciptakan dominasi ${ }^{28}$.

Dominasi yang dilakukan oleh para pemilik modal tersebut dengan berbagaikepentingannya menyebabkan masyarakat lokal tersisihkan dan kalah bersaing. Praktik-praktik spasial di Kulon Progo, khususnya di sekitar Bandara NYIA ditujukan bagi pertumbuhan industri kapitalistik. Proses perubahan dari suasana desa menjadi suasana kota mendorong berlangsungnya segregasi sosial di dalam ruang masyarakat. Dalam hal ini, kelas menengah ke atas meneguhkan keberadaannya akan rasa nyaman dan prestise dengan difasilitasi oleh cara-cara produksi dari tangan kapitalisme yang menciptakan ruang sosial, sehingga menimbulkan perbedaan yang mencolok terkait wilayah-wilayah, bangunan, dan fasilitasfasilitas yang dimilikinya ${ }^{29}$.

\section{Konstruksi dan Kontestasi Pembangunan Ekonomi}

Ruang ekonomi tidak hanya memproduksi komoditas, melainkan masyarakat berhadapan dengan perkembangan kapitalisme lanjut. Menurut Henri Lefebvre, suatu produksi tidak hanya terjadi dalam suatu ruang, namun ruang itu sendiri yang diproduksi. Ruang menjadi komoditas melalui rangkaian proses abstraksi yang dilakukan oleh pemilik otoritas politik maupun para pemilik kapital ${ }^{30}$.

Pembangunan Bandara NYIA menciptakan ruang sosial baru yang di dalamnya terjadi kontestasi pembangunan ekonomi. Model yang diterapkan untuk memenuhi kebutuhan ekonomi masyarakat bukan lagi

\footnotetext{
${ }^{28}$ Ida Bagus Brata, 'Kapitalisasi Ruang Terbuka Tradisional Sebagai Komoditas', in Makalah Seminar (Lembaga Penelitian dan Pemberdayaan Masyarakat (LPPM) Unmas Denpasar, 2016), p. 131.

29 Ardyan M. Erlangga, 'Ruangmu Belum Tentu Istanamu', in Ruang Kota (Yogyakarta: EKSPRESI Buku, 2011), p. 35.

30 Christian and Desmiwati, 'Menuju Urbanisasi Pulau Kecil: Produksi Ruang Abstrak Dan Perampasan', p. 51.
} 
model kebersamaan, melainkan menerapkan model kompetisi. Setiap orang berlomba-lomba untuk mendapatkan keuntungan dari pembangunan NYIA beserta pertumbuhan ruang-ruang baru di sekitarnya. Sebagaimana yang diinginkan oleh Pemerintah Kabupaten Kulon Progo, meskipun tengah memperjuangkan produk lokal untuk masuk ke bandara, namun prosesnya Pemkab terlebih dahulu melakukan seleksi terhadap sejumlah Usaha Mikro, Kecil, dan Menengah (UMKM) untuk menempati gerai komersial di dalam area NYIA. Pihaknya juga menetapkan tarif sewa tempat, dan mewajibkan standar tertentu bagi produk kuliner, seperti kemasan yang menarik dan layak sesuai dengan kebutuhan pasar ${ }^{31}$.

\section{Ruang Abstrak Desa Glagah}

Hilangnya sisi historisitas ruang yang beralih ke ruang abstrakdiungkapkan oleh Hadi Sentono, yaitu sebagai berikut:

"Di sini sudah enak, bisa menanam apa pun tergantung yang musim, tanah sendiri bebas apa pun ditanam tumbuh. Biasanya saling bantu sesama warga, kadang kalau saya mau tanam cabai ya dibantu tetangga sebelah, sebaliknya juga begitu. Sekarang sudah tanahnya diambil, kalau cukup beli tanah baru kan gak deket lagi dengan tanah tetangga dulu"32.

Pernyataan Hadi Sentono di atas menandakan bahwa ruang sosial di Desa Glagah telah berubah menjadi ruang abstrak. Sisi historis dan relasi sosial yang telah terbangun secara turun temurun telah berubah menjadi ruang kota dengan kawasan wisata dan disampul dengan jargon "mercusuarnya dunia". Corak dan karakter tradisional seperti kekuatan kolektif diganti dengan corak produksi kapitalis ${ }^{33}$.

Menurut Henri Lefebvre, ruang geometri sejatinya adalah abstraktif dan menyamakan antara yang abstrak dan konkret. Hal ini tentu saja tidak memadai karena ruang yang dialami tidak mungkin sama dengan abstraksi (sebuah hasil dari conceived space). Pada bagian ini timbul kesalahanyang

\footnotetext{
31 Tribun, 'Kopi Kulon Progo Masuk Bandara', Tibun Jogja, p. 11.

32 Wawancara dengan Hadi Sentono, di Glagah tanggal 10 Januari 2019.

33 Christian and Desmiwati, 'Menuju Urbanisasi Pulau Kecil: Produksi Ruang Abstrak Dan Perampasan', p. 53.
} 
memunculkan marginalisasi dan alienasi ${ }^{34}$. Pembentukan ruang abstrak di Desa Glagah merupakan asas dari akumulasi kapital, sebab abstraksi ruang serta intervensi spasial melalui pembangunan melipatgandakan produksi dan sirkulasi kapital secara cepat-ruang itu menjadi alat produksi dan terdapat berbagai jaringan pertukaran komoditas.

\section{Kontradiksi Ruang NYIA}

Perebutan ruang dari masyarakat merupakan persoalan yang fundamental karena memperbesar ketimpangan dan kesenjangan sosial, karena penguasaan ruang di Desa Glagah terkonsentrasi pada segelintir kelas saja. Kehadiran bandara NYIA memaksa masyarakat untuk melepaskan ruang-ruang milik mereka. Tindakan pemerintah atas pembangunan ini sebagai salah satu cerminan bahwa negara rela mengorbankan masyarakat Kulon Progo demi tangan-tangan kapitalis dapat melakukan ekspansi, eksploitasi, dan akumulasi kapital. Bagi pemerintah, kehadiran NYIA mendongkak sektor ekonomi negara. Namun bagi masyarakat, kehadiran bandara justru menghancurkan sumbersumber kehidupan dan nilai-nilai sosial di Desa Glagah.

\section{Reproduksi Ruang Agama}

Proses tersebut dalam pandangan Henri Lefebvre dikenal dengan produksi ruang diferensial, suatu produksi ruang untuk memulihkan kembali ruang abstrak yang telah didominasi oleh kepentingan kapitalisme. Ruang abstrak berupaya mengendalikan dan menghomogenisasi setiap individu dan segala sesuatu, sementara ruang diferensial mengutamakan perbedaan dan kebebasan dari aspek-aspekpengendalian ${ }^{35}$. Dalam proses produksi ruang diferensial di Desa Glagah ini, secara fisik berbentuk masjid yaitu sebagai ruang suci atau tempat beribadahnya umat Islam. Masjid menjadi salah satu ruang untuk menampung segala kepentingan yang berkaitan dengan kebutuhan rohani dan jasmani-mencari keseimbangan antara kebutuhan religius dan kebutuhan dunia. Umat muslim di Desa

\footnotetext{
34 Stuart Elden, 'There Is a Politics of Space Because Space Is Political: Henri Lefebvre and the Production of Space', Radical Philosophy Review, 2007, pp. 109-10 <https://doi.org/10.5840/radphilrev20071022>.

35 George Ritzer, 'Teori Sosiologi: Dari Sosiologi Klasik Sampai Perkembangan Terakhir Postmodern', Yogyakarta: Pustaka Pelajar, 2012, p. 528.
} 
Glagah sama seperti umat Islam pada umumnya, yakni melaksanakan ibadah di masjid kemudian dilanjutkan dengan melantunkan doa-doa yang berhubungan langsung dengan kehidupan di dunia dan akhirat. Umat muslim memanjatkan doa secara khusuk, dan memohon supaya dikabulkan segala permintaannya.

Pada akhirnya, masjid sebagai ruang diferensial masyarakat kembali didominasi oleh sebagian kelas saja. Hanya orang yang mempunyai kekuasaan terhadap masjid yang dapat memperoleh atau mempunyai hak untuk mengelola dan memanfaatkan uang masjid yang terkumpul dengan dalih merawat dan pengembangan masjid. Hal ini mengindikasikan bahwa Masjid Nurul Jannah kembali menjadi ruang untuk memproduksi kapital. Dengan kata lain, masyarakat muslim Desa Glagah cenderung masuk dalam lingkaran kapitalisme.

\section{SIMPULAN}

NYIA sebagai simbol sebuah konflik kepentingan antara kalangan pemerintah dan masyarakatnya. Konflik yang terjadi dengan adanya NYIA ini membentuk sebuah ruang sosial, baik ruang agama, sosial, ekonomi, politik maupun budaya, yang di masa yang akan datang akan merubah struktur yang sudah mapan dan mentradisi di masyarakat. Meskipun awal pembangunannya menuai pro dan kontra pada akhirnya yang mempunyai modal harus menundukkan yang kalangan biasa. Ini semacam dejavu masa lalu yang menyejarah. Pada akhirnya ruang yang sudah terbentuk dan penaklukan yang sudah terjadi, ini menjadi sebuah realitas adanya. Realitas yang jika dilihat secara subtanstif mempunya nilai-nilai perjuangan gagal yang mengerikan, dan kemenangan yang menjijikkan. Ketidakberpihakan pemerintah kepada masyarakat lokal-sebagai pemilik ruangmengakibatkan masyarakat Desa Glagah terasingkan dari ruang sosialhistorisnya. 


\section{DAFTAR PUSTAKA}

Akademia, New Yogyakarta International Airport: Pesisir Selatan Temon-Kulon Progo, 2017

Aminah, Siti, 'Konflik Dan Kontestasi Penataan Ruang Kota Surabaya', MASYARAKAT: Jurnal Sosiologi, 2016

Azhar, Zul, 'Kajian Lingkungan Dan Perencanaan Pembangunan', in Buku Ajar Fakultas Ekonomi Universitas Negeri Padang, 2017

Brata, Ida Bagus, 'Kapitalisasi Ruang Terbuka Tradisional Sebagai Komoditas', in Makalah Seminar (Lembaga Penelitian dan Pemberdayaan Masyarakat (LPPM) Unmas Denpasar, 2016)

Bungin, Burhan, Metodologi Penelitian Sosial

Christian, Yoppie, and Desmiwati Desmiwati, Menuju Urbanisasi Pulau

- - -, 'Menuju Urbanisasi Pulau Kecil: Produksi Ruang Abstrak Dan Perampasan', Journal of Regional and Rural Development Planning, 2018 <https://doi.org/10.29244/jp2wd.2018.2.1.45-63>

Elden, Stuart, 'There Is a Politics of Space Because Space Is Political: Henri Lefebvre and the Production of Space', Radical Philosophy Review, 2007 <https://doi.org/10.5840/radphilrev20071022>

Erlangga, Ardyan M., 'Ruangmu Belum Tentu Istanamu', in Ruang Kota (Yogyakarta: EKSPRESI Buku, 2011)

Fakih, Mansour, Runtuhnya Teori Pembangunan Dan Globalisasi Cet. VIII (Yogyakarta: Pustaka Pelajar, 2013)

Gulsyan, Muhammad Azka, 'Ekonomi-Ekonomi Yang Lain: Mewacanakan Ekonomi Dan Melihat Kembali Pembangunan' <indoprogress.com>

Harvey, David, Imperialisme Baru Genealogi Dan Logika Kapitalisme Kontemporer (Sleman: Resist Book, 2010)

Hidayat, Rahmad, 'Potensi Pelanggaran Hak Atas Properti Privat Dalam Pembangunan Fasilitas Publik (Kasus Pembangunan Bandara International Kulon Progo)', Journal of Governace, 2017

Indonesia, Kementerian Keuangan Republik, 'Perekonomian Indonesia Dan APBN 2017'<www.kemenkeu.go.id> [accessed 2 September 2018] 
Kustiningsih, Wahyu, 'Kelompok Rentan Dalam Pembangunan Kawasan Kota Bandara Di Kulon Progo: Studi Kasus New Yogyakarta International Aiport (NYIA)', Jurnal Pemikiran Sosiologi, 2017

Lefebvre, Henry, The Production of Space; Translated by Donald Nicholson, Urban Studies (Oxford: Blackwell, $<$ https://doi.org/10.1080/00420989220081001>

Nurpita, Anisa, and dkk, 'Dampak Alih Fungsi Lahan Terhadap Ketahanan Pangan Rumah Tangga Tani Di Kecamatan Temon Kabupaten Kulon Progo', Jurnal Gama Societa, 2018

Pamungkas, Anjar Mukti Yuni, ‘Manajemen Konflik Dan Negosiasi Wajah Dalam Budaya Kolektivistik (Konflik Pembangunan Bandara Di Kulon Progo)' (Universitas Diponegoro, 2015)

Ritzer, George, 'Teori Sosiologi: Dari Sosiologi Klasik Sampai Perkembangan Terakhir Postmodern', Yogyakarta: Pustaka Pelajar, 2012

Soehadha, Moh., Metodologi Penelitian Sosiologi Agama (Yogyakarta: Bidang Akademik UIN Sunan Kalijaga, 2008)

Tim Penutur Selamatkan Bumi, 'New Yogyakarta International Airport: Pembangunan Tanpa Demokrasi, Pembangunan Tanpa Rakyat' <selamatkanbumi.com>

Tribun, 'Kopi Kulon Progo Masuk Bandara', Tibun Jogja

Peraturan Presiden Republik Indonesia Nomor 3 Tahun 2016 Tentang Percepatan Pelaksanaan Proyek Strategis Nasional.

Wawancara dengan Bapak Arto, warga Desa Glagah, di Glagah tanggal 10 Januari 2019.

Wawancara dengan Hadi Sentono, petani, di Glagah tanggal 10 Januari 2019.

Wawancara dengan Kasimin, di Glagah tanggal 10 Januari 2019.

Wawancara dengan Hadi Sentono, di Glagah tanggal 10 Januari 2019 